\title{
SER Y VALOR
}

Iuvat integros accedere fontes

de rer. nat. I, 927

No es siempre fácil dar razón cabal de la aparición de ciertas disciplinas filosóficas hasta cierto punto inéditas - por lo menos nominalmente-, y sobre todo cuando tal fenómeno acontece después de veinticinco siglos de filosofar. El progreso o el retroceso alternativamente recurrentes, el volver incesantemente al punto de partida, la meditación asumida y reasumida, y siempre con originaria y radical responsabilidad, sobre los mismos temas, son caracteres del pensamiento filosófico que apenas si sorprenderán al no iniciado en la filosofía, pero no al que sabe bien que éste es el destino de la inteligencia humana cuando se arroja a la conquista de lo primero y lo último, de lo que por definición está más allá de toda experiencia inmediata. Todo esto va de suyo en la gran aventura. Pero la perplejidad es real, y para el fílósofo no menos que para el profano, cuando de repente parece descubrirse una nueva región del ente o su sentido, como si hasta entonces hubiera estado oculta al afán inquisitivo del hombre.

En ocasiones ha podido darse de estos hechos un diagnóstico hasta cierto punto preciso, y sobre todo cuando el transcurso del tiempo permite apreciar exactamente la situación. Hoy es posible decir, por ejemplo, por qué no hubo filosofía de la historia en la antigüedad clásica, no obstante la gran historia que entonces se hizo y se escribió. Para aquello, en efecto, y además de vivir la historia e incluso de escribirla, era necesaria la conciencia histórica, es decir, la visión de un mundo en el cual lo único, lo singular y lo irreversible fuesen lo decisivo. Ahora bien, esta visión no fue posible dentro de una cultura y para una mentalidad que de un modo u otro buscó siempre su salvación en lo formal, lo normativo y lo universal; una cultura para la cual, sin exceptuar al mayor de sus filósofos, la inmovilidad era el valor supremo, y después de ella lo que más se le aproximaba, como las rotaciones eternamente circulares y uniformes de los astros incorruptibles. Era menester aguardar a la revelación o manifestación de actos tan singulares, irrevocables y definitivos como la Creación, la Caída, la Encarnación, la decisión voluntaria, tan terriblemente irreversible en ciertas criaturas; era menester que todo esto actuara en la conciencia humana con tan tremendo impacto para que verdaderamente pudiera saberse lo que es la historia.

¿Podríamos dar una explicación semejante, de tan limpios perfiles, con respecto a la axiología? El nombre por lo menos, data apenas, como quien 
dice, de nuestro siglo. Lavelle ${ }^{1}$ atribuye a Urban ${ }^{2}$ su difusión si no su invención; y en todo caso sería difícil encontrar precedentes nominales más allá del Grundriss der Axiologie de Eduardo von Hartmann, publicado en 1907. Precedentes reales ciertamente los había, pues ya Kreibig había propuesto el nombre, que no corrió con fortuna, de Timología; y por último, parece haber consenso general en cuanto a reconocer en Lotze (1817-1881) el padre de la filosofía de los valores, así no sea sino por haber introducido, antes que otro alguno, los conceptos de valor y validez (Wert-Geltung) como categorías autónomas y aun irreductibles a cualquier otra categoría o trascendental ontológico.

Todo esto, empero, es cosa apenas de ayer (en la historia de la filosofía un siglo es un menguado tracto temporal) y la pregunta surge, apremiante, de cómo fue posible que tanto tiempo pasara sin que los hombres, y en particular los filósofos, se hubieran hecho cuestión expresa de lo que en la misma medida que el ente, o por ventura más aún, es objeto primordial de la reflexión filosófica, o sea su relación con nuestra participación y nuestro obrar.

Lo primero que ocurriría contestar $-\mathrm{y}$ es, en efecto, la respuesta usual del espíritu perezoso o reaccionario-, es que la nueva disciplina no era, cuando más, sino una nueva agrupación de viejos temas con otra terminología u otro método; una especie de compilación o codificación, bajo ciertas categorías generales, de las axiologías regionales que ya estaban allí, aunque con otro nombre, en todas las esferas de estimación y sentido: en ética, en estética, en filosofía de la religión, etc. Pues para no mencionar sino unos cuantos nombres y doctrinas sobresalientes ¿no había ya desde Sócrates una reflexión muy de propósito sobre los valores de la conducta humana, y no habían sido después estos valores minuciosamente investigados y descritos en la ética aristotélica? ${ }^{3}$ Con los valores estéticos por su parte ¿no habían hecho lo propio Platón, Aristóteles, Longino, Plotino, el Pseudo Dionisio y tantos más? $\mathrm{Y}$ aun el orden jerárquico de los valores, y por si esto fuera poco, la expresión misma de valor, bien que en formas verbales ¿no estaba ya tal cual en aquella página, siempre sobrecogedora, de los tres órdenes pascalianos? ¿Qué podían, pues, hacer Lotze y la escuela de Baden y los axiólogos de Viena después de esta tradición espléndida, sino elaborar una escolástica en èl peor sentido de la palabra, asunto de nuevos rótulos y nuevas formalidades sin el menor contenido creador?

Algo hay de verdad en estas apreciaciones, pero tomadas en todo su hermetismo, son sin duda injustificadas. Como a menudo se ha observado con toda razón, no hay ningún gran movimiento histórico: religioso, político,

1 Traité des valeurs, Paris, 1951; I, pág. 24.

2 Valuation, its nature and laws, New York, 1909.

3 N. Hartmann, Ethik, Berlin, 1949; pág. 417: Sie sind (las virtudes) die Werte des menschlichen Verhaltens selbst. 
filosófico, etc., que pueda tener curso y dejar huella más o menos profunda si no responde a una necesidad real del espíritu o si no lo animan sino vivencias superficiales o bastardas. No hay, por ejemplo, una sola religión viviente que haya sido fundada y mantenida con designios exclusivos de superchería; ni hay tampoco ninguna filosofía con acusada impronta en la historia, en cuya formación y desarrollo no intervengan otros factores fuera del virtuosismo verbal o el espíritu de sistema. Ahora bien, la filosofía de los valores, aun dado caso que actualmente estuviera ya en sus postrimerías (cosa por lo demás muy probable) tiene en su haber una suma impresionante de obras de singular prestigio, con grandes concepciones y profundos análisis; y así no fuese sino por estos últimos, aunque en lo otro y lo mayor hubiera fallado su meta, representa un caudal de pensamiento al que no es de ningún modo lícito permanecer ajeno y con el que de hoy en adelante hay que contar. ¿Cómo entonces no ver en el origen y desenvolvimiento de esta filosofía el más inequívoco signo de autenticidad?

Con la axiología ha pasado, me parece, lo mismo que con el existencialismo, y no obstante que el contenido doctrinal de uno y otro movimiento sea tan diferente, por no decir contradictorio. Por el solo hecho de haber bajado hasta las charlas de café (a donde, dicho sea de paso, bajan también cosas tan serias como la religión y la política) no quieren muchos ver en el existencialismo sino esnobismo y palabrería, cuando en verdad representa, por lo menos en sus grandes maestros, la decisión heroica de enfrentarse de una vez por todas a realidades tremendas que sólo la cobardía humana -a la que por lo visto no escapan tampoco los filósofos- había podido disimular. La filosofía misma había sido arrastrada en la caída de la cotidianidad, y fue el existencialismo quien la hizo volver al modo de la existencia propia. Pues de la propia suerte la filosofía de los valores surgió también de la necesidad impostergable de conquistar o reconquistar realidades sin las cuales la vida humana no tiene sentido en absoluto. ¿O es que no podemos llamar "realidad" a lo que, sea en sí mismo lo que fuere, clama, como el valor, por su realización?

Todo el punto, sin embargo, está en saber si en este caso hemos de hablar de conquista o de reconquista, y por demás está decir que la opción en uno $u$ otro sentido deja intacto el pathos en absoluto auténtico del movimiento. Dando por sentado, por lo menos provisionalmente, que esas "dignidades" u "honores" ( $a \xi\llcorner\omega j \mu \alpha \alpha$ ) de la vida humana, que son literalmente los valores, estaban en aquel momento ausentes de la conciencia filosófica ¿tratábase de un continente hasta entonces ignoto, o tan sólo de una obnubilación circunstancial del espectador, y por más que la unidad temporal de la circunstancia haya podido englobar varios siglos?

Mi más sincera convicción ha sido siempre la de que esto último, y no aquello, fue lo que ocurrió puntualmente. Lo cual no implica que por ello 
solo caigamos en la posición reaccionaria de que antes hablé, pues toda reconquista se emprende siempre con nuevas armas y con mayor experiencia, y los hallazgos, en definitiva, son a la postre mucho más ricos que el inventario original. Esto, empero, a condición de saber coordinar lo uno con lo otro, de injertar lo nuevo en lo antiguo, pues de otro modo, y por muchos que sean los logros parciales, se acabará a la postre, como le está pasando a la axiología que es pura axiología, en un callejón sin salida. Pero es tiempo ya de justificar todas estas afirmaciones, para lo cual hemos de mostrar sucintamente las circunstancias histórico-filosóficas que en determinado momento llevaron a la apoteosis solitaria del valor, y cómo debe operarse el retorno al ser, manantial primero e indeficiente del valor. ${ }^{4}$

\section{La devaluación del ente}

Que en el pensamiento filosófico occidental, el ente estuvo tradicionalmente permeado de valor, es poco menos que un lugar común en la historia de la filosofía. Ens et bonum convertuntur, dijeron los escolásticos, resumiendo en esta máxima una tradición que remontaba por lo menos hasta Platón. La Idea del Bien, en efecto, principio del ser y del conocer, sol del mundo inteligible y también del mundo sensible, es ciertamente -por mucho que pueda controvertirse aún su identificación con Dios- la más cumplida e inescindible síntesis de ser y valor. Más aún, pudiera decirse que el valor tiene en ella una acusada primacía sobre el ser, como quiera que, según dice Platón, la Idea del Bien está más allá de toda esencia o sustancia concreta, y a todas las sobrepuja en poder y dignidad. ${ }^{5}$ Nada puede ser si no es bueno en alguna medida, y el valor es así el título a la existencia de toda entidad que positivamente podamos designar como tal.

Esta concepción, una de las más sublimes seguramente del entendimiento humano, pervive en Aristóteles, y aun allí mismo donde más de propósito se pone el Filósofo a impugnar la Idea platónica del Bien. La polémica no nos interesa aquí, e inclusive puede sostenerse con buenas razones que los antagonistas son más bien Espeusipo y Xenócrates, en cuyas manos había sufrido aquella Idea una depauperación radical. Como quiera que sea, Aristóteles afirma en ese mismo lugar que el bien se dice en tantos sentidos como el ente, ${ }^{6}$ o sea, ni más ni menos, el ens et bonum convertuntur de los medievales. El ente es en Aristóteles, por supuesto, objeto de predicaciones múltiples, pero en cada una de ellas estará ínsito el valor correspondiente. Más aún, la misma primacía del valor sobre el ser, que creemos percibir en Platón, se mantiene en Aristóteles, por cuanto que la causa final, que es para cada

4 Lavelle, op. cit., I, pág. 305: L'être est la source de la valeur.

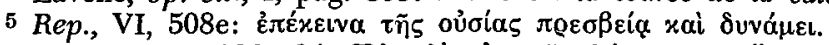

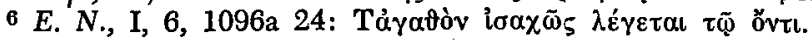


ente su bien, es de todas la primera y principal, omnium potissima; aquella que puede dar acabada razón de cada cosa, por gobernar el despliegue completo de las virtualidades del ente y la esencia.

Dejemos de momento la escolástica, que será en seguida objeto de tratamiento sistemático, y pasemos a indicar someramente las causas por las cuales el ente fue literalmente depreciado, devaluado, eviscerado de toda estimación y dignidad.

El proceso ha sido descrito mil veces y por eminentes pensadores, $y$ todavía Lavelle lo resume inmejorablemente al decir que el ser no puede ser extraño al valor sino cuando se ha acabado por identificarlo con una cosa, lo que equivale a debilitarlo, a privarlo de su vitalidad, a matarlo en suma. ${ }^{7}$ El ente mortificado: lêtre mortifié, dice Lavelle; y como él podríamos también nosotros devolver a nuestro verbo su probable sentido prístino, el que ciertamente tuvo en latín: mortificare, mortuum facere. ¿Cómo fue, entonces, que se mató al ente? Pues sencillamente al dejarlo reducido a la condición de cosa, de cosa extensa y por tanto inerte y vacía, por obra de la revolución intelectual cuyos frutos fueron la ciencia moderna y la filosofía cartesiana. Pensamiento y extensión: si una y otra cosa estaban divorciadas en el hombre mismo ¿cómo no iban a estarlo en el resto de la creación? El valor es, de cualquier modo que se le considere, la proyección del espíritu; y siendo así ¿qué valor podía tener en adelante un mundo, el de los sentidos por lo menos, que no era ya más - como lo había sido desde Platón hasta el simbolismo medieval-, la fulguración del espíritu?

Esta reducción del ente a categorías propias de la ciencia físico-matemática podía estar muy en su lugar para el solo fin de fundar la legalidad de un saber de dominio sobre la naturaleza, y este saber era una conquista incuestionablemente legítima del espíritu humano. Para este solo propósito metodológico puede concederse que era más bien perturbante que coadyuvante el operar con categorías como las formas sustanciales o las causas finales, y que en su lugar debía hacerse sobre todo con las otras categorías de extensión y movimiento. Mas la filosofía, como saber del ente en general, debió haber conservado su soberanía, y el ente, a su vez, su antigua plenitud de valor y sentido.

No fue así desgraciadamente, como lo sabemos harto bien; y en la imposibilidad de describir aquí las etapas de este proceso, bastará con recordar cómo en Kant se consuma, al parecer irrevocablemente, el divorcio entre ser y valor o deber ser (Sein, Sollen), quedando el segundo sin contenido material alguno y dependiente de un a priori puramente formal. Introducir en este ámbito una "materia" cualquiera - y midiendo con el mismo rasero, en esta calificación, cosas tan distintas como bienes empíricos y valores-,

7 Lavelle, op. cit., I, pág. 302: L'être n'est étranger d̀ la valeur que si on lidentifie à une chose; c'est-à-dire si on le mortifie. 
era, según Kant, hacer depender la ley moral de algo contingente, y convertir, por ende, en hipotético el imperativo categórico.

Como no era posible que con esta solución se conformara el espíritu humano, que no vive de sí mismo ni de su propia legislación, sino de los objetos intencionales en que se proyecta y de que se nutre, la razón práctica de Kant es ya en Lotze, como lo dice él mismo, sinónima de razón que percibe sentimentalmente el valor (praktische Vernunft, Wertempfindende Vernunft). Toda la axiología está ya aquí, en esta expresión y en esta equivalencia, como un intento denodado por ir más allá de Kant, pero sin renegar de él, y en todo caso dejando viva la escisión radical entre razón teórica y razón práctica, y correlativamente entre el ente y esta otra misteriosa entidad (el lenguaje, como vemos, no nos permite salirnos del ente) que, a beneficio de inventario, se bautizaba con el nombre de valor. No era una representación especulativa (de esto no había ni que hablar) sino algo que el espíritu podía captar, como decía Lotze, en estados de complacencia y displicencia. ${ }^{8}$

Por estos caminos fue la filosofía de los valores, filosofía medularmente germánica en el nombre, en la cosa, en sus presupuestos filosóficos y en sus más conspicuos representantes: Lotze, Windelband, Rickert, Meinong, Ehrenfels, Brentano, Scheler, Eduardo y Nicolai Hartmann... En gran medida, seguramente, enriqueció el patrimonio espiritual del hombre, y sobre todo - para mí es éste su mayor acierto y su legado perdurable - devolvió al sentimiento el papel que le corresponde en la aprehensión profunda y eficaz del valor, y que con tanta ceguera le había negado el racionalismo. Pero con todo ello, el espíritu reclama algo más que las brillantes descripciones de la fenomenología, $\tan$ genialmente puesta por Max Scheler al servicio de la filosofía de los valores, y algo más que la restauración de la intencionalidad sentimental. Reclama también, y acaso sobre todo, una fundamentación radical, una metafísica del valor, un retorno al arxê en que ser y valor se unifican, por venir uno y otro, en última instancia, de quien es con identidad absoluta Ens summum y Summum bonum. Ahora bien, si en la fenomenología del valor y los valores realizó la axiología conquistas imperecederas, en la metafísica del valor fracasó rotundamente - digo, por supuesto, la axiología propiamente dicha, con pretensiones de absoluta autonomía y sin raíces en la tradición. En este capítulo, en efecto, da qué hemos llegado, en fin de cuentas? En Scheler, a una clausura completa de este reino a la razón, "tan ciega al valor como el oído a los colores"; en Hartmann a esto mismo, y sobre esto a una hipostatización completa del valor, ya que los valores son, para este filósofo, esencias o esencialidades (Werte sind Wesenheiten) que tienen, en su constitución, un "en si" y un "para sí" (An sich und für sich) ni más ni menos que el ra̛’aưtó de la İdea platónica. ¿Hemos ganado mucho, al cabo werden.

8 Mikrokosmos, Leipzig, 1876; I, pág. 269: In Lust und Unlust des Wertes inne zu 
de tantos avatares, con haber desembocado en un neoplatonismo, o con mayor precisión, en un platonismo inentitativo, alógico y sentimental? Podrá ser esto muy germánico, pero la filosofía no tiene por qué estar enfeudada ni siquiera a la mentalidad más filosófica de los tiempos modernos.

Del mismo modo.que en el otro gran campo del ser - y es ésta la gran esperanza de nuestro siglo- ha de insertarse la fenomenología de la existencia en la metafísica del esse, también aquí la fenomenología del valor ha de fundirse con la metafísica del bonum, del bien que se convierte con el ente, y sin ser, no obstante, sinónimo con él. Y ha sido también en Alemania donde se han llevado ya a cabo los primeros ensayos de esta síntesis fecunda, volviendo, con nueva perspectiva y más profunda visión, a la vieja doctrina de las propiedades trascendentales del ente. Es el único camino, en mi modesto entender, por donde puede efectuarse esta Aufhebung (que es, también aquí, cancelación, conservación y superación) de la filosofía de los valores; y en lo que sigue no pretendo otra cosa que resumir, o cuando más glosar, los resultados de esas investigaciones emprendidas por mentes más lúcidas y mejor informadas. ${ }^{9}$

\section{El ente $y$ sus trascendentales}

A quienes han puesto en entredicho la posibilidad de una ontología al mismo tiempo general y material, bastaría con oponerles, como simple dato objetivo y sin juzgar aún de su valor intrínseco, esta doctrina sobre las propiedades trascendentales del ente, uno de los monumentos de la filosofía patrística y medieval.

Antes que aquellos doctores, Aristóteles había postulado resueltamente la existencia de una ontología semejante al decir, en un lugar bien conocido de la Metafísica, que: "Hay una ciencia que estudia el ente en cuanto ente y las propiedades que por sí mismo le son inherentes." 10 Aristóteles, con todo, no fue capaz de describir de manera rigurosa y sistemática estas propiedades inherentes al ente por su misma constitución, no obstante que en sus escritos figuren abundantes textos que fueron después de gran ayuda a los escolásticos. El porqué de esta aparente deficiencia de su genio metafísico, trataremos, si es posible, de esclarecerlo después.

Como en este artículo no pretendo hacer historia de una cuestión filosófica, sino abordarla directamente, nos colocaremos sin más en lo que puede

9 Merecen sobre todo particular mención los trabajos del P. Iohannes B. Lotz, S. I., principalmente: Sein und Wert (Zeitschrift für katholische Theologie, Innsbruck, 1933), así como el curso profesado en la Gregoriana: De proprietatibus entis transcendentalibus, y cuya sinopsis mimeográfica he podido utilizar por cortesía del autor, a quien desde aquí hago público mi agradecimiento.

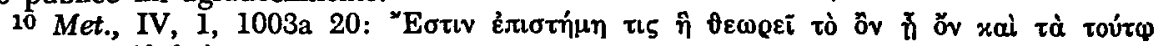

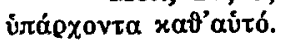


considerarse el locus classicus en esta materia, o sea el texto de Santo Tomás donde aparecen, acabadamente fundadas y configuradas, estas propiedades: que pertenecen al ente en cuanto tal.

En el principio mismo de las Cuestiones Disputadas sobre la Verdad, ${ }^{11}$ se plantea Santo Tomás el problema de cómo es posible predicar algo del ente mismo sin que la predicación sea una mera tautología, toda vez que el ente, como dijo Avicena, es aquello que como lo más patente concibe ante todo nuestro entendimiento, y en lo cual, además, se resuelven en última instancia todas sus concepciones. ${ }^{12}$

No es menester justificar aquí lo bien fundado de este aserto, tan propio de la filosofía tradicional, de que es en el ente donde se resuelven en último extremo todas las concepciones del entendimiento. La axiología radical podría oponer aquí precisamente que la categoría o noción de valor es irreductible a la de ser o ente, y que, como se ha dicho, los valores no son, sino que valen. "De ellos — dice Aloys Müller- no se puede predicar el ser." 13 ¿Mas por qué? Pues sencillamente porque, como en seguida añade, lo que el ser es para los objetos sensibles, esto mismo es el valer para los valores. ${ }^{14}$ De modo, pues, que si el valor puede postularse como irreductible al ser, es a consecuencia de haber previamente reducido el ser, con toda arbitrariedad, a una determinada región ontológica, o sea, como dijimos antes, de haber cosificado el ente. Por otra parte, es el mismo Aloys Müller quien considera los valores como pertenecientes a una de tantas esferas de la realidad (Wirklichkeit), bien que luego contraponga esta realidad a la otra realidad (Realität, Dinglichkeit) propia de los objetos sensibles. Habría así, por encima del Sein y del Gelten (esta filosofía germánica hay que tratarla con sus propios términos) un concepto más alto y común a aquellos otros, que sería el de Wirklichkeit, por la que a su vez habría que entender, según la definición propuesta por Eisler, todo aquello que puede constituir el contenido de cualquier experiencia posible. ${ }^{15}$ Todo es, pues, cuestión de entendernos; y lo que hace al caso es que la noción del ente fue en los escolásticos tan amplia por lo menos como todo eso, ya que no se extendía tan sólo a todos los objetos propiamente dichos, sino aun al llamado ente de razón, y aun de pura razón, sin la menor consistencia real y ni siquiera ideal. Y por último, y en fin de cuentas, si los axiólogos del Gelten inentitativo han de decir otra cosa que esto de que los valores valen, y hacer siquiera una feno-

11 de Ver. qu. 1 , a. 1, c. Todas las citas a continuación, salvo indicación en contrario, están tomadas de este mismo lugar.

12 Illud autem quod primo intellectus concipit quasi notissimum, et in quo omnes conceptiones resolvit; est ens.

13 Einleitung in die Philosophie, $2^{\text {a }}$ ed., pág. 35.

14 op. cit., loc. cit.: Was also das Sein für die sinnlichen Gegenstände ist, das ist das Gelten für die Werte.

15. Wörterbuch der philosophischen Begriffe, $3^{\mathrm{a}}$ ed., pág. 1841: Den Inhalt einer möglichen Effahrung Bildende. 
menología del valor, ya que no una metafísica, les será preciso decir, como lo hacen de hecho abundantemente, que los valores son esto o lo otro, por donde tampoco escapan a esta ultima resolutio de todos nuestros conceptos en el ente. De un modo u otro, pues, y como en los días de Parménides, el pensamiento no puede desentenderse del ente.

Por estas comprobaciones inmediatas, en suma, no precisa detenernos más en este punto; y por otra parte, aunque sólo se aceptara como hipotética aquella proposición, lo que interesa aquí mostrar es cómo el ente, cualquiera que sea su ámbito, es también bueno o valioso. Así, pues, el problema es tan sólo por lo pronto el de determinar cómo es posible predicar algo del ente sin mera sinonimia o tautología, ya que, al parecer, toda ulterior determinación del ente es también ente.

A esto responde Santo Tomás diciendo que, por ello mismo, al ente no puede añadirse nada que tenga con respecto a él extrañeza o heterogeneidad de naturaleza, al modo como la diferencia se añade al género o el accidente al sujeto, ya que toda naturaleza es por esencia un ente. ${ }^{16}$ ¿Cómo podrá entonces hacerse esta adición? No hay sino una vía posible, y es, dice Santo Tomás, en cuanto que por estas ulteriores determinaciones expresamos algún modo del ente no expresado por el nombre del ente mismo. ${ }^{17}$ Todavía aquí, sin embargo, hay que hacer una importante restricción, y es la de que este modo no debe ser un modo especial (specialis modus), o sea una determinación intracategorial con arreglo a la cual el ente se constituye en determinada categoría o grado de entidad, como cuando hablamos, por ejemplo, del ente por sí ( $p e r$ se ens), calificación que de inmediato constituye al ente en el género de la sustancia. Debe, por el contrario, ser uno o varios modos que con absoluta generalidad sean consiguientes a todo ente (modus generaliter consequens omne ens) y que, por otra parte, no estén manifiestos a nuestro entendimiento en el solo concepto del ente. .

Ens stomitur $a b$ actu essendi, dice Santo Tomás, acogiéndose una vez más a la autoridad de Avicena: el ente se toma, como expresión o concepto, del acto de ser, o con mayor propiedad tal vez, del acto de existir. Ens es el participio activo de esse, y significa, por tanto, el acto del verbo: Ens simpliciter dictum significat actu esse. Si podemos o no predicar la entidad de lo que no está en acto de existir, o con qué restricción o reducción a aquel acto, es cuestión que Santo Tomás deja aquí intacta. Lo único que le importa dejar sentado es que el solo nombre o concepto de ente no revela por sí solo, fuera del actus essendi, nada más sobre la estructura interna del ente. Esta revelación no podrá venir sino de estos otros modọs que acompañan, con

18 Sed enti non potest addi aliquid quasi extranea natura, per modum quo differentia additur generi, vel accidens subiecto, quia quaelibet natura essentialiter est ens.

17 Secundum hoc aliqua dicuntur addere supra ens, in quantum exprimunt ipsius modum, qui nomine ipsius entis non exprimitur. 
absoluta generalidad, a todo ente. Con esto entramos en el núcleo mismo de lo que podríamos llamar la deducción de los trascendentales del ente; deducción que Santo Tomás lleva a cabo de la siguiente manera.

Estos modos generales, nos dice, tendrán que ser aquellos que son consiguientes a todo ente considerado en primer lugar en sí mismo, y después en orden o relación a otro $u$ otros entes..$^{18}$

En cuanto a lo primero, del ente en sí mismo podemos predicar dos propiedades, por afirmación o negación absolutas respectivamente. Por afirmación, la esencia que compete a todo ente, y que Santo Tomás designa aquí con el nombre de res. Por negación, la indivisión intrínseca del ente, corolario inmediato de su identidad consigo mismo (mientras sea tal ente, y propia también, por tanto, del ente temporal) y es lo que se llama la unidad o el unum del ente.19

Mas si ahora, en segundo lugar, consideramos el ente en su orden o relación con otro o con otros entes, tal relación a su vez será o con respecto a todo otro ente, o bien a un ente de tipo especial. Por lo primero, tendremos la división del ente de todos los demás, y por ella será llamado el ente algo, o mejor quizás, como término más correspondiente al aliquid latino, algo otro. $^{20} \mathrm{Y}$ por lo segundo a su vez, tendremos no ya la división solitaria del ente, sino su conveniencia o avenimiento con otro ente, el cual por su parte, dice Santo Tomás en un pasaje de maravillosa profundidad, no podrá ser sino un ente muy especial que por su naturaleza pueda convenir, avenirse o entrar en comunicación o contacto (todo esto hay en los términos convenientia o convenire) con todo ente. ${ }^{21}$

Ahora bien, este ente, sigue diciendo el santo, es el alma, el ente abierto a todo ente sin limitación alguna, y que por ello, por su intencionalidad potencialmente infinita, es en cierto modo, como dijo Aristóteles, todas las cosas. ${ }^{22}$ Hubiera estado mejor, es cierto, haber hablado aquí del alma intelectual, $\cdot$ o todavía mejor, del espíritu, para el cual solamente la intencionalidad no tiene términos ni riberas, pero es indudable que a esto se refirieron precisamente Santo Tomás y Aristóteles. Y como en esta alma, concluye aquél, hay una potencia cognoscitiva y otra apetitiva, la conveniencia o concierto del ente con el entendimiento constituye la propiedad trascendental de la verdad (verum), en tanto que la conveniencia con el apetito es lo que llamamos el bien (bonum).

18 Uno modo secundum quod consequitur omne ens in se; alio modo secundum quod consequitur unumquodque ens in ordine ad aliud.

19 Nihil enim est aliud unum quam. ens indivisum.

20 Secundum divisionem unius ab altero; et hoc exprimit hoc nomen aliquid: dicitur enim aliquid quasi aliud quid.

21 Secundum convenientiam unius entis ad aliud; et hoc quidem non potest esse nisi accipiatur aliquid quod natum sit convenire cum omni ente.

${ }_{22}$ Hoc autem est anima, quae quodammodo est omnia, sicut dicitur in III de Anima. 
Estos cinco trascendentales del ente (res, unum, aliquid, verum, bonum) pueden aún, en la opinión común de la Escuela, reducirse a tres. Res, en efecto ( $y$ lo dejamos así, en su rica plenitud nativa, imposible de verter, ni siquiera aproximadamente, en nuestro vocablo "cosa") designa aquí lo que esa voz quiere decir en su acepción originaria, o sea lo que ante todo podemos pensar o decir del ente (res-reor), es decir, su esencia o quididad: lo que cada ente es; $y$, por lo tanto, es noción contenida formalmente, aunque de manera implícita, en el mismo concepto de ente. Ahora bien, los trascendentales deben añadir algo conceptualmente nuevo, algo que rebase aún a lo contenido formaliter implicite en la noción del ente. Así, pues, res se reduce a ens; y por manera análoga el aliquid se reduce al unum, por cuanto que la indivisión del ente consigo mismo implica su división con respecto al otro. Por esto dirá un día Suárez con toda razón que si hemos de hablar con propiedad y no forjar distinciones que no son en absoluto necesarias, no hay sino tres pasiones o afecciones del ente, a saber uno, verdadero y bueno. ${ }^{23}$ Por otra parte, en el mismo Santo Tomás, y justamente allí donde más le interesa esta doctrina para las cuestiones filosóficas o teológicas de mayor momento, prevalece la fórmula ternaria.

Unum, verum, bonum... Estos son los modos por los cuales el ente revela a nuestro entendimiento algo de su riqueza y dinamismo. Revelación y no evolución, porque el ente no es para esta filosofía, como para Hegel, la más pobre de las determinaciones, o aun la ausencia de toda determinación, sino todo lo contrario. Esta explicitación del ente en sus propiedades trascendentales (pues trascienden todos los géneros en que el ente se coarta en esta o aquella categoría) no obedece sino a la finitud de nuestro entendimiento, incapaz de apresar en un solo concepto todos aquellos atributos. $\mathrm{Y}$ por esto dijeron los escolásticos que entre el ente y sus propiedades inmediatas no hay distinción real, sino apenas una distinción de razón, y aun ésta mínima, y análoga en todo a la que se da entre Dios y sus atributos, o sea la posibilidad de predicaciones infinitas dentro de la simplicidad absoluta.

\section{Los trascendentales del ente y el Ente trascendental}

Esta referencia al Ente, que es única y máximamente ente, no es aquí una mera comparación, sino que es ella la que nos abre el camino para entender a su luz y en toda su concreción, doctrinal e histórica, esto que vamos declarando, como también para resolver ciertas antinomias que han quedado latentes en lo hasta ahora dicho.

El ente, hemos dicho, es verdadero y bueno por cuanto que hay en él

23 Disp. met., III, 2, 3: Breviter dicendum est, si proprie loquamur et non fingamus distinctiones minime necessarias, tres tantum esse proprias passiones entis, scilicet unum, verum, bonum. 
una ordenación esencial a otro ente dotado de intencionalidad cognoscitiva y apetitiva. Mas con esto parece introducirse una dualidad originaria en el ente mismo, ya que el espíritu es apenas en cierto modo todas las cosas, y para ser más precisos, todas las que no son él. La verdad y el valor no podrían entonces constituirse sino por una proyección del espíritu sobre la realidad (como lo afirman numerosos axiólogos) y consecuentemente no podríamos decir con todo rigor que lo verdadero y lo bueno son simplemente convertibles con el ente. El ente no sería verdadero sino para una inteligencia, ni bueno sino para un apetito. Ahora bien, si toda dualidad debe fundarse en último extremo en la identidad (proposición en la cual Santo Tomás estaría en completo acuerdo con Hegel) es evidente que esta identidad no podrá encontrarse sino en el Ente absoluto que es al mismo tiempo el Espíritu absoluto, y cuyo ser es, con identidad igualmente absoluta, su entender y su querer. Entendemos estos términos, por supuesto, de acuerdo con Santo Tomás y no con Hegel, por más que el primero, una vez más, podría haber suscrito esta otra profunda intuición del segundo, al expresar que el ser quiere decir en última instancia infinitud y espíritu: Sein sagt letzlich Unendlichkeit und Geist.

He ahí por qué los trascendentales del ente no sólo no tienen su impleción cabal sino en el Ente infinito, en el Ente propiamente trascendental, ${ }^{24}$ sino que, sin referencia a él, ni siquiera podrían predicarse, en la medida que sea posible, del ente finito. De no existir, en efecto, sino entes de esta especie, no habría sino modos especiales y categoriales del ente, y toda predicación que pretendiera trascender estos modos no tendría como correlato sino una mera abstracción, la más pobre efectivamente de todas, que sería esta vez el concepto de ente. Esta es la verdadera razón de por qué en las ontologías circunscritas exclusivamente al ente finito (como en la de Nicolai Hartmann, por ejemplo) no hagan falta sino las categorías, los géneros supremos, y no estos otros conceptos que serían un mero entretenimiento si no arraigaran en el Ente que trasciende todos los géneros, y en cuya eminencia y simplicidad absolutas están todo el ser y todo el valor. $\mathrm{Y}$ por ello puede decir Santo Tomás, en un texto capital, que estos nombres de ente y bueno, uno y verdadero, preceden absolutamente, de acuerdo con nuestro modo de entender, a los otros nombres divinos. ${ }^{25}$

Más concretamente aún, y en lo que atañe al verum y al bonum, es preciso hacer ver con mayor detalle cómo de ninguno de ellos es posible predicar su identidad radical con el ente si prescindimos del Ente que es el último origen y fundamento de todo ente actual o posible y de sus trascendentales.

24 Por trascender en absoluto toda determinación categorial, como siendo el ipsum Esse subsistens. ¿Habrá que decir que ciertos términos, usados también en otras filosofías, no tienen, en ésta y en aquéllas, sino apenas una comunidad lexicológica?

25 Sent. I, d. 8, qu. I, a. 3: Ista nomina: ens et bonum, unum et verum, simpliciter secundum rationem intelligendi, praecedunt alia divina nomina. 
Toda verdad es, según la Escuela, una adaequatio rei et intellectus, pero la verdad trascendental, ésta de que aquí hablamos, no puede consistir en la adecuación o conformidad entre la cosa y nuestro entendimiento (relación siempre contingente y precaria), sino que debe darse con respecto al entendimiento que no está, como el nuestro, medido por la cosa, sino que es medida de la cosa misma, es decir, el intelecto divino. ${ }^{26}$ Scientia Dei est causa rerum: de todas sin excepción, aun de los actos libres; y toda esencia actual o posible es por ello mismo, y en infinitos grados, término imitativo de la esencia divina. Por ello es todo ente, aun la materia prima en lo que tenga de entidad, radicalmente inteligible, racional y verdadero, con esta verdad que está en la cosa misma, como lo había dicho, antes que Heidegger, San Hilario: Verum est manifestativum et declarativum esse. La única diferencia entre una y otra posición estaría en que esta patencia o revelación del ente sólo es posible, para los escolásticos, en función de la relación trascendental (luego volveré sobre este concepto de fecundidad incalculable) que hay en todo ente finito, en su esencia y existencia, con la idea divina.

En cuanto al bien trascendental, es más imposible aún, si cabe, mostrar su conversión real con el ente prescindiendo de la otra relación trascendental que éste tiene con el Bien sumo, que es su causa ejemplar, su causa eficiente y su fin último. De este Bien fue del que ante todo dijo Dionisio $-\mathrm{y}$ lo mismo había dicho, más o menos, Platón-, que se efunde a sí mismo (Bomum est diffusivum sui) y por esto fueron llamadas buenas, desde el principio del mundo, todas las criaturas: Et erant valde bona. En un plano empírico o aun fenomenológico será siempre imposible hacer ver cómo todo ente sin limitación alguna puede ser perfectivo del espíritu humano ( $y$ comunicar perfección está en la esencia misma del valor) como no sea tal vez en el enriquecimiento de las especies intencionales. De manera incondicional sólo refulge el valor en lo que de algún modo es símbolo y traslado del Valor subsistente, imagen suya o por lo menos vestigio.

Por aquí podremos ya ver por qué, según antes dijimos, no pudo la filosofía antigua llevar a su perfección esta doctrina de los trascendentales, con la firmeza de trazo y la hondura metafísica con que lo hizo la filosofía medieval. Para ello le faltó la concepción de la causalidad eficiente y ejemplar de Dios en todo lo creado. A lo segundo llegó apenas Platón, y muy dudosamente Aristóteles; a lo primero, ninguno.

\section{La refracción trinitaria}

Pero a tal punto se acusa la impronta teológica en esta metafísica del ente, que ya no sólo por el lado de la teología natural, sino también por el de la teología revelada puede aquélla destacarse aún con mayor nitidez.

26 de Ver. $q u$. 7, a. 2, c: Res naturales mensurant intellectum nostrum, sed sunt 
Tengo para mí que éste es uno de los puntos en que la teología más propiamente dicha, la teología positiva, ha influido más vigorosamente en una doctrina que por otra parte ha conservado, a pesar de este impacto, toda su consistencia filosófica; y no me explico cómo no ha sido esto desarrollado más largamente, como en otras cuestiones, por historiadores de la filosofía medieval, como Gilson y su escuela. Será tal vez porque ha faltado, más que en otras zonas de influencia, el documento histórico; pero esta misma ausencia podría ser un indicio de que por lo natural y espontáneo del influjo, por recibirlo tan de suyo como el aire y la luz, apenas si se consignó, o no se consignó del todo, en textos escritos.

Desde San Agustín por lo menos fue tendencia constante de la patrística y la escolástica buscar en las criaturas analogías divinas, y más expresamente aún, analogías trinitarias; operación a la que estimulaba tanto la corriente platónica, según la cual este mundo sensible es réplica del mundo inteligible, como también, y acaso más, el corolario inmediato del dogma creacionista, a la luz del cual pudo verse cómo estaba, en la obra prima de Dios, "sellado el resplandor de su rostro". Esta simbólica, con todo, se detuvo al parecer, o se detuvo de preferencia, en la imagen propiamente dicha de Dios, esto es en el hombre, como aparece abundantemente en el tratado agustiniano de Trinitate. Hubo quizás un sentimiento reverencial que impidió ver en todo ente en general la refracción no sólo del poder divino, sino de la vida íntima de Dios y de su misteriosa fecundidad $a b$ intra. Y, sin embargo, el hecho es, una vez más, que esta doctrina que hemos descrito del ente en general como animado de este dinamismo, de esta fecundación para la inteligencia, la voluntad y el sentimiento, no acaba de explicitarse cumplidamente sino con referencia a Dios no sólo sub ratione entis, sino sub ratione deitatis, esto es, con vistas al misterio del Dios trino y uno. ${ }^{27}$

El ente sin otra calificación es, como hemos visto, el ámbito dentro del cual se constituyen los otros trascendentales. Ahora bien, si el ente es de este modo no la noción hegeliana carente de toda determinación, y por ello mismo confinante con la nada, sino todo lo contrario, un surtidor inagotable de dinamismo y plenitud, es por su referencia, como a su causa total, al Ens a se, al ipsum Esse subsistens, al Acto puro de existir. Y esta noción, a su vez, aunque válida de suyo en el terreno de la filosofía pura, la elaboró de hecho la escolástica, como lo ha demostrado concluyentemente Gilson, ${ }^{28}$ a la

mensuratae ab intellectu divino, in quo sunt omnia creata, sicut omnia artificiata in intellectu artificis.

27 Como nada está más lejos de mi ánimo que arrogarme títulos de descubridor, quiero precisar aún que lo único que ha faltado en este punto en la escolástica (por lo menos en la bibliografía que he podido consultar) es una acabada sistematización, de la que, por lo demás, encontramos más que un esbozo en filósofos católicos de nuestros días, como, por ejemplo, Lotz, en su curso inédito sobre las propiedades trascendentales del ente, y Edith Stein, principalmente en Endliches und ewiges Sein, Louvain-Freiburg, 1950.

28 Cf. principalmente: L'esprit de la philosophie médiévale. 
luz de textos escriturarios como el del Exodo, donde Dios, hablándole a Moisés, se define a sí mismo como "El que es". ${ }^{29}$ Este es el Ente único cuya esencia es su existencia, y cuyo nombre no significa ninguna forma determinada, sino el ser mismo en toda su infinitud en todos los órdenes posibles; como un piélago, dice Santo Tomás citando al Damasceno, infinito y sin término. ${ }^{30}$ No es ya la Idea o el Pensamiento de la filosofía antigua en sus más altas concepciones, sino el Acto absoluto de existir. Por esto la ontología posterior no va a ser ya una ontología esencialista, sino, en el mejor sentido de la expresión, existencialista; y por esto el ente en general, antes de toda determinación esencial, tiene en sí una potencia de irradiación y fecundación. Esta concepción se sustenta, pues, en el Dios uno del Exodo y no en el de la Metafísica. Pero en segundo lugar, y sin dejar de ser uno, este Dios se revela en el Nuevo Testamento como Dios tripersonal; y cada una de las Personas de la Trinidad corresponde puntualmente a cada uno de los tres trascendentales del ente: unum, verum, bonum. Veámoslo seguidamente.

Aunque no como nombre estrictamente personal, sino "por apropiación", San Agustín y Santo Tomás refieren expresamente la unidad a la persona del Padre, pues así como lo uno es el trascendental preoperativo, que se constituye en el ente mismo sin referencia a otros entes ni a sus operaciones intencionales, así también el Padre es en la Trinidad la Persona que no presupone otra alguna, el Principio sin principio. ${ }^{31}$

En cuanto a la concordancia entre la verdad trascendental y la persona del Hijo, los textos teológicos y filosóficos son esta vez de una abundancia tal que apenas si nos es posible hacer aquí una mera alusión a lo más medular de esta teología del Verbo consustancial al Padre y causa ejemplar de la creación entera. Por este su "doble rostro", como dice Edith Stein, es verdaderamente el logos, el intermediario entre el Ser y los entes, y el que comunica a éstos sentido y racionalidad.

"En el principio era la Palabra": así solemos traducir la sentencia inicial del cuarto evangelio; pero la expresión queda en este caso no sólo a infinita distancia de lo expresado, sino que ni siquiera logra ya captar la profunda

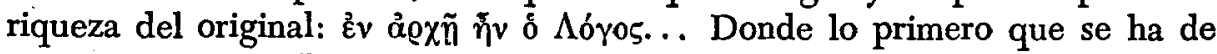
notar es que este "principio" no tiene sólo el sentido de absoluta eminencia supratemporal que tiene en el Génesis, sino muy probablemente también el que implica este mismo término de arxê desde los tiempos de la filosofía jónica, es decir, lo primero y más íntimo y más radical de todo ente, que sería allá el Logos, in sinu Patris, y aquí el logos, en la estructura nuclear del ente.32

20 Exod. III, 13: Sic dices eis: Qui est, misit me ad vos.

30 Sum. theol., I, 13, $11 \mathrm{c}$.

31 Sum. theol., I, 39, 8, c: Nam unitas dicitur absolute, non praesupponens aliquid aliud. Et ideo appropriatur Patri, qui non praesupponit aliquam personam, cum sit principium non de principio. 
En cuanto al Logos mismo, y más en este lugar, toda descripción o perífrasis será por siempre irremediablemente deficiente. "Este nombre -dice Crampon en su comentario al texto joánico- responde, aunque excediéndolos, a la Sabiduría del Antiguo Textamento y a la Palabra de la antigua literatura talmúdica." "Para el espíritu griego - dice por su parte Leoncio de Grandmaison- agrupábase alrededor de la palabra Logos todo lo serio, razonable, hermoso, ordenado, conveniente y legítimo, musical y armonioso." 33 Toda esta multiformidad de acepciones podría estar hoy para nosotros implícita en lo que, bajo la inspiración de la filosofía alemana, llamamos sentido (Sinn) y por esto Edith Stein no duda en afirmar que por este término puede también traducirse el Logos joánico, y con referencia explícita a este mismo Logos, agrega que no hay ningún sentido que no tenga en él su hogar o domicilio desde la eternidad. ${ }^{34}$

Por este Logos, sigue diciendo el evangelista, "fueron hechas todas las cosas”, y por él tienen, por ende, inteligibilidad, razón, vida interior, luz $z^{35}$ y sentido. O lo que es lo mismo, y para volver a nuestro cuento, el ente es radicalmente verdadero, porque el Logos eterno, que es a la vez la perfecta expresión del Padre y el perfecto ejemplar de las criaturas, es, con propiedad absoluta, la Verdad. ${ }^{36}$

En otros nombres asimismo, que como personales o apropiados predica la teología del Hijo de Dios, como son los de Imagen, Belleza, Sabiduría, Esplendor, Espejo (imago, pulchritudo, sapientia, splendor, speculum) pudo fundarse la opinión, sostenida aún por numerosos escolásticos, ${ }^{37}$ de que lo bello (pulchrum) sería también uno de los trascendentales del ente. Nos abstenemos por ahora de entrar siquiera en tan apasionante problema, y lo único que cumple aquí advertir es que aun por parte de aquellos que reducen - pulchrum a uno u otro de los otros dos trascendentales (verum, bonum) o ambos a la vez, la doctrina es común en cuanto a ver en la verdad ontológica, y por aquella referencia a su primer origen, ese splendor o claritas que es la nota más cierta de la belleza, y cuyo velamiento eventual no sería imputable sino a nuestras potencias cognoscitivas. Dicho en otros términos, la verdad del ente es de suyo refulgente e irradiante, y su aprehensión por

32 Aun prescindiendo de toda mediación sobrenatural, es más que verosímil que por su larguísima permanencia en Efeso -medio siglo aproximadamente- haya podido San Juan dar al arxé el sentido que aún conservaría en la ciudad de Heráclito y en la región nativa de la filosofía.

33 Christus, Manual de historia de las religiones, Barcelona, 1929; pág. 910. hätte.

34 op. cit., pág. 409: Es gibt ja keinen Sinn, der nicht im Logos seine ewige Heimat

35 Luz y vida ( $\varphi \tilde{\omega}_{\varsigma}, \zeta \omega \eta \dot{)}$ ) son, como se ha observado, los términos posiblemente de mayor recurrencia en el evangelio del Logos.

36 Ioan., XIV, 6: Ego sum via, et veritas et vita.

37 Como Raeymaeker, Maritain, Edith Stein y otros muchos. 
parte nuestra, y tanto más mientras más cabal sea, redunda en ese placet que es propio tanto del sentimiento estético como de lo que von Hildebrand y Hartmann llaman la respuesta al valor (Wertantwort). ¿Cómo dudar siquiera, si se comparte esta cosmovisión, que el ente esté transido de valor?

Del Espíritu Santo, por último -y con mayor razón aún cuando, como en la teología católica, se afirma su procesión del Padre y del Hijo-, se predica como nombre personal el de Amor, y por apropiación los de Bien o Bondad, por ser el bien término del amor, ya que, como dice Santo Tomás, amar es querer bien a alguien: velle bonum alicui. ${ }^{38} \mathrm{Y}$ aun prescindiendo del Filioque, la misteriosa espiración del Espíritu Santo se entendió comúnmente como una procesión de amor (pues por generación intelectual era imposible, dado que no hay sino un solo Hijo de Dios) y esta concepción remitía directamente a ver el término de la espiración divina como Bien.

En la misma estructura interna del ente está, pues, impresa, como dice Lotz, una profundissima imago Smae. Trinitatis, sólo que sin procesión ni distinción real — como la hay en la oposición relativa divina- entre los atributos del ente. $Y$ en lo que mira a su absoluta solidaridad y convertibilidad recíproca, es de recordarse aún, con referencia a la Trinidad, la doctrina teológica de la circunincesión, ${ }^{39}$ es decir, la radicación íntima, sin mengua de su oposición personal, de todas y cada una de las divinas personas en todas y cada una de las otras: Pater totus in Filio et totus in Spiritu Sancto, etc., como dice el Concilio florentino. Pues otro tanto, y con todas las diferencias y reservas, entre los trascendentales del ente, los cuales, conservando su distinción de razón, se incluyen mutuamente y nunca se separan entre sí: mutio se includunt, nec unquam derelinquunt se.

\section{La relación trascendental y el valor}

Mas todavía nos queda algo por decir en esta misma materia, y lo creemos de todo punto inexcusable, pues en ello precisamente podría fundarse, en nuestro concepto, una ontología del valor, una ontología que pudiera acoplar la doctrina escolástica con intuiciones inimpugnables de la axiología moderna.

Digo, pues, que para declarar de algún modo la compatibilidad entre la oposición personal y la unidad absoluta de naturaleza en la Trinidad, los escolásticos, Santo Tomás sobre todo, acudieron al concepto de.lo que denominaron relación trascendental. La relación, en efecto, era hasta entonces lo

38 Sum. theol., I, 39, 8, c: Bonitas autem, cum sit ratio et obiectum amoris, habet similitudinem cum Spiritu divino, qui est amor.

30 Circumincessio y cirmuminsessio, dicen los teólogos, traduciendo respectivamente

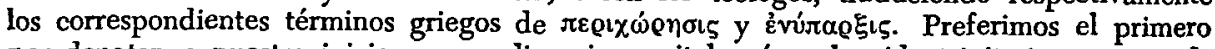
por denotar, a nuestro juicio, mayor dinamismo vital, así en la vida trinitaria como en la estructura del ente en general. 
que en Aristóteles había sido: un accidente predicamental; algo real sin duda, pero no sustancial, pues su carácter constitutivo, su esse ad, deriva su título de realidad del esse in que, como todo accidente, tiene la relación en la sustancia, y que, por esto mismo, le viene de ella. El esse ad, por tanto, este respecto u ordenación a otra cosa (ordo ad aliud) es, en la relación predicamental, algo adventicio a la sustancia; algo,en suma, accidental. Pues bien -y éste fue aquí el tránsito genial-, Santo Tomás postuló otra relación, real desde luego, supremamente real, pero no categorial sino trascendental, es decir, un orden o respecto a otra cosa, pero no adventicio, sino incluido, entrañado en la esencia de la cosa misma: ordo ad aliud in essentia rei inclusus. ${ }^{40}$ El esse $a d$, en esta nueva relación, no es realmente distinto del esse in, sino que es uno y lo mismo, con distinción apenas de razón. De este modo, y en lo tocante en primer término al misterio trinitario, pudo Santo Tomás afirmar que las personas divinas no son sino relaciones trascendentales subsistentes en una sola naturaleza, la cual es en el Padre incomunicada y comunicable, en el Hijo comunicada y comunicable, y en el Espíritu Santo comunicada e incomunicable. Y por todo ello, además, hay identidad absoluta entre las relaciones y la esencia divina, y oposición excluyente, a la vez, de las relaciones entre sí. Paternidad, filiación, espiración activa y espiración pasiva, son en Dios la misma esencia divina en absoluto, pero no lo mismo en su oposición relativa.

La relación trascendental, excogitada históricamente bajo el apremio del gran dogma cristiano (fides quaerens intellectum) se desbordó después a otras cuestiones filosóficas o filosófico-teológicas, en todas las cuales se reveló asimismo extraordinariamente fecunda. De la esencia al ser, de la materia a la forma, del alma a su cuerpo, y aun después de la muerte (pues lo que está en la esencia de un término guarda su relación al otro, aun desaparecido este último) fue posible predicar la relación trascendental y conceptualizar de este modo problemas del mayor interés para la filosofía cristiana.

Pues la misma relación transcendental podría fundar, según creo, la ontología del valor - como también, por otra parte, la de la verdad-, y es ésta, si no me engaño, la intuición central de la escolástica en esta materia, ${ }^{41}$ y que está ya en la definición tomista del Bien como tráscendental. ${ }^{42}$ Lotz, es verdad, se muestra un poco renuente a subsumir por completo el concepto de valor bajo el de relación, pero es porque teme que se piense en la relación predicamental. Pero cuando se precisa bien que se trata de esa otra rela-. ción que no añade nada realmente al ser, ni en lo divino ni en la criatura, sino

40 Cf. Garrigou Lagrange, De Deo trino et creatore, págs. 74 sigs.

41 Paul Siwek, "Problema valoris in philosophia S. Thomae et Cartesii", Gregorianum, vol. XVIII, 1937, págs. 518 sigs.: Ratio formalis boni seu valoris in relatione collocanda est, quam res aliqua ad appetitum habet. Hubiera sido deseable que explicara Siwek de qué relación se trata.

42 Sum. theol., I, 16, 1, c: Bonum est in re, in quantum habet ordinem ad appetitum. 
que es el ser mismo in ordine ad aliud, Lotz es el primero en afirmar que el valor es así, esencial e indisolublemente, una y otra cosa, lo absoluto y lo relativo. ${ }^{43}$

El valor sería así el orden o relación trascendental del ente a todo apetito en general; orden incluido, por supuesto, en la misma realidad del ente: Ordo entis ad appetitum, in ipsa realitate entis inclusus. Esta sería la definición que, salvo juicio mejor, me atrevería a proponer. Ella sola, tomada escuetamente, dice bien poca cosa; pero los antecedentes históricos y doctrinales que la informan podrán haberle comunicado - por lo menos así lo espero- enjundia y sentido. De estos antecedentes, por lo demás, es dicha noción, de hecho y de derecho, en todo solidaria; o dicho de otro modo, que se nutre de una cosmovisión filosófico-teologica en cuya vigencia o decadencia está aquélla irrevocablemente comprometida. El valor no podrá arraigar en el ser, o brotar de él como de un surtidor, sino en la medida en que el ser de cada ente sea de algún modo una refracción del Ser que por su fecundidad infinita $-a b$ intra y ad extra - es causa eficiente, ejemplar y final de toda fecundidad entitativa y de toda vivencia de valor.

\section{La aprehensión del valor}

Por ser el valor, por una parte, el ser mismo, y en razón, por la otra, de la incapacidad de nuestras potencias cognoscitivas para tener una intuición adecuada del ser (a la que no se llega sino aproximativamente después de haberlo explicitado en sus trascendentales) es el valor, como dice Lavelle, lo más patente y lo más misterioso. Lo primero, porque no se deduce del ente, sino que nos es dado con el ente mismo y en una noción igualmente original y primaria, como lo reclama con toda razón la axiología moderna. Y lo segundo, porque a causa de la inadecuación susodicha, no se nos revela el valor por la misma vía $\longrightarrow$ no por ella sola - por que aprehendemos otras determinaciones en la estructura del ente.

Si el valor, en efecto, es una ordenación al apetito, está dicho sin más que su captación adecuada, plena, concreta, no es sólo cosa del entendimiento, sino también, y por ventura más, del otro término de la relación, esto es, del apetito. Y por apetito no ha de entenderse aquí tan sólo el apetito racional de la voluntad, de la razón pura práctica, sino, con él y en una intencionalidad dinámicamente una, el apetito irracional también, y sobre todo en esa zona intermedia, tan indefinible pero tan real, en que lo lógico comunica con lo alógico, y el espíritu con la carne y la sangre; ${ }^{44}$ esa zona que los griegos llamaron ขvuós, los alemanes Gemüt, y que nosotros los latinos, a falta de otra

43 Sein und Wert, pág. 602: Der Wert ist somit weder etwas Absolutes, Relationsloses, noch eine blosse Beziehung, er besagt wesentlich und untrennbar beides.

44 Mittenbereich, wo der Geist ins Blut geht, dice Romano Guardini. 
palabra más adecuada, estamos designando, cada día con mayor énfasis, como el "corazón".

En este punto, según dijimos, tiene toda o casi toda la razón la axiología moderna, al haber reivindicado, frente al pensamiento racionalista, la legalidad del sentimiento como órgano intencional del valor; y es una lástima que la escolástica haya dejado fructificar en otros campos lo que estaba latente en su propio patrimonio. Fue una negligencia no más, por otra parte, que no hay tampoco por qué exagerar, pues el verdadero culpable fue el auténtico racionalismo, el de Spinoza por ejemplo, para el cual los sentimientos y afectos constituyen propiamente la "servidumbre humana", aun los más nobles de todos, como la simpatía y la piedad. De estas aberraciones del espíritu humano hemos vuelto hace mucho tiempo, venturosamente.

Sin una adecuación o resonancia sentimental por parte del sujeto, no habrá jamás una aprehensión plenaria del valor. Ningún razonamiento podrá demostrar la beileza de una obra de arte a quien no la sienta; ni la justicia es un valor sino para los justos (esto es tan viejo como Aristóteles por lo menos) ni la santidad sino para los santos. "Quien no participa en el valor no sabrá jamás lo que el valor es", dice Lavelle, y por ello, "el valor no es un concepto ni un objeto, y sólo se conoce cuando es vivido". ${ }^{5}$ No por esto, sin embargo, desconoce el añorado filósofo francés la identidad radical entre ser y valor, como tampoco la función que compete a la inteligencia en cuanto a "esclarecer a la vez el sentimiento y el querer".46 Trátase tan sólo de afinar el modo de captación de esto que está en las entrañas del ser, pero no tan manifiesto para el solo intelecto humano, sino que nuestra naturaleza por entero ha de estar en lo que por entero la compromete, en lo que no tiene la distancia indiferente de una proposición matemática, sino que es algo imperativamente constrictivo de la conducta. "El valor — dice aún Lavelle- es el ser mismo definido como objeto de un supremo interés, es decir, de un acto de amor." 47 Y en otra parte aún: "EI valor es esta intimidad del ser que no se puede percibir por de fuera, y que no se puede descubrir sino desde dentro, viviéndolo y haciéndolo uno suyo." 48 El valor es una relación, un llamamiento no sólo al logos anímico, como la verdad teórica, sino a toda el alma, y ha de ser abrazado, como diría Platón, con toda el alma.

Con estas apreciaciones concurre en buena parte la escolástica de nuestros días, aunque sin desplazar por ello la función que tiene también la inteligencia en la percepción del valor. El conocimiento abstracto de la relación, en efecto, es de orden intelectual; y así, el animal persigue bienes que lo son realmente para él, pero no los aprehende como bienes. En su vivencia concreta e inmediata, sin embargo, el valor es un dato transintelectual, accesible

45 op. cit., I, pág. 248.

46 op. cit., I, pág. 194.

47 op. cit., I, pág. 430.

48 op. cit., I, pág. 303. 
a la sensibilidad $o$ al sentimiento, según los casos. ${ }^{49}$ La conciencia fundamental del valor, dice Lotz, es intelectual, ${ }^{50}$ pues es sólo el entendimiento el que puede mostrar, con completa objetividad e independientemente de las motivaciones irracionales del apetito, la conveniencia de tal bien o tal acto al sujeto. Aquí también, como desde Brentano hasta Husserl, la representación es el acto fundante. Estos contenidos objetivos de valor, sin embargo, estos Wertgehalte, aunque perceptibles de suyo intelectualmente, no serán eficaces, cumplidos, vividos en suma, sino cuando, y en fuerza una vez más del orden de los mismos al apetito, sobreviene por parte del sujeto la respuesta adecuada del apetito. ${ }^{51}$ En términos husserlianos podríamos decir que la percepción intelectual del valor es apenas una intención incumplida, y que su cumplimiento te viene de la respuesta emocional. Esta es, para el valor, su vivencia impletiva (Erfullungsertebnis), su presencia "en persona". La primera sería así, de acuerdo con el símil propuesto en otra conexión por el propio Husserl, como el título de crédito, como la letra girada a la vivencia emocional, y carece de valor mientras por esta respuesta no es aquélla aceptada y cumplida.

¿No nos corrobora esto mismo, por otra parte, la experiencia más cierta? ¿No es bien nítida, por ejemplo, la percepción intelectual que todos los cristianos tenemos del valor de la pobreza cuando leemos el evangelio, y no continuamos bien apegados a las riquezas? Y si en los santos tiene la misma lectura un efecto del todo distinto ¿no es por el incendio de su corazón bajo la moción de la gracia, y por más que la representación intelectual pueda ser, también aquí, el acto fundante?

Es a la luz de todas estas evidencias irrebatibles en la fenomenología del valor, como la escolástica, sin dejar de ser, como siempre, la defensora de la inteligencia, ha prestado mayor atención a la intencionalidad sentimental, revitalizando, por ejemplo, aquellos textos tomistas en que se nos habla del conocimiento per connaturalitatem, ${ }^{52}$ o como diríamos hoy, la afinidad entre el contenido valioso del objeto y la constitución moral o afectiva del sujeto percipiente. $Y$ esta connaturalitas, lejos de ser una vía inferior de conocimiento, es, por el contrario, lo típico del saber más alto en absoluto, tanto por su correlato como por el modo de aprehensión, que es la sabiduría como don del Espíritu Santo. Esta connaturalidad con las cosas divinas, dice Santo Tomás, se produce en nosotros por la caridad, ${ }^{53}$ que es cuanto podría decir o reclamar el más acérrimo defensor del Fühlen intencional. Asimismo, y por

49 Siwek, op. cit., loc. cit.: Cum iterum ratio finis relationem intrinsece dicat, valorem non nisi $a b$ intellectu secundum suam abstractam rationem apprehendi posse patet; a facultatibus sensitivis eum tantum concrete attingi.

50 Das grundlegende Wertbewusstsein ist intellektuell.

51 Lotz, art. cit.: Wie der objektive Wert durch die Hinordnung auf das Streben konstituiert wird, so ist auch die ihm gemäse Antwort von Seiten des Subjekts der Akt des Strebens.

22 Sum. theol., II-II, 45, 2, c.

os Ibid.: Connaturalitas ad res divinas fit per caritatem. 
toda la ética tomista, está la complacentia affectuum, la respuesta emocional al valor, que diríamos hoy, como condición necesaria para el cumplimiento efectivo del acto moral. No era, pues, tan ajena esta filosofía, como podría creerse a primera vista, al reconocimiento de la función sentimental en la aprehensión del valor. Con la autoridad que aun por su función magisterial no cabe negarle, ha sido el Papa Pío XII quien, en la encíclica Humani generis principalmente, ha defendido a la filosofía escolástica del cargo de atender exclusivamente al papel de la inteligencia, con menosprecio del que corresponde a la voluntad y a los afectos del ánimo. ${ }^{54}$

La metafísica del ente y sus trascendentales, esta doctrina que no sin asombro vemos aún calificar como "la parte más estéril de la metafísica tradicional", ${ }^{55}$ es por el contrario el único fundamento seguro para compaginar en la unidad del objeto aquella doble intencionalidad, la representativa y la práctica, que Husserl, por su intelectualismo, no pudo conciliar, como tampoco, por su parte, Scheler, al derivar al otro extremo de erigir en algo absoluto e incondicionado la intencionalidad no significativa. En esta otra visión, en cambio, lo mismo que es verdadero e inteligible aparece también, al establecerse la relación dinámica con la voluntad y el sentimiento, como bueno y valioso.

En este campo también, por consiguiente, puede columbrarse, como no muy lejana tal vez, la síntesis por que anhelamos, la gran síntesis del siglo $\mathrm{xx}$, entre fenomenología y metafísica. Una sin la otra corren el riesgo de ser, respectivamente, o una mera técnica descriptiva de vivencias sin arraigo en el ser, o un discurso en el vacío. De su fusión, en cambio, de su coordinación jerárquica, resultará una ontología al mismo tiempo plena y profunda; y en lo que atañe al valor específicamente, su reimplantación en el ser, pero no como formalidad vacía, sino con toda la riqueza capaz de informar cumplidamente los anhelos del hombre. "El valor - dice Pietro Romano- es la afirmación y revelación del ser en una experiencia espiritual." 56 Lo primero continúa siendo patrimonio de la filosofía antigua; lo segundo, en cambio, su apofántica, es la aportación de la modernidad.

\section{ANTonto Gómez Robledo}

54 Hum. gen., par. 50: Ac denique philosophiae nostris traditae scholis hoc vitio vertunt, eam nempe in cognitionis processu ad intellectum unice respicere, neglecto munere voluntatis et affectuum animi. Quod quidem verum non est.

55 Eduardo Nicol, Metafísica de la expresión, México, 1957; pág. 31.

56 Ontologia del valore, Padova, 1949; pág. 135. 